the late 19 th and early 20 th centuries, which became known as the stratemeyer Syndicate. This corps of writers produced such memorable series as the Rover Boys, Tom Swift, Bobbsey Twins, Hardy Boys, and Nancy Drew.

\section{Two hundred Chinese language books}

were donated to the University of South Carolina from the Embassy of the People's Republic of China. The materials will support the university's programs for students in business, sciences, liberal arts, languages, and literature. This is the second group of materials the Chinese Embassy has presented to the university in recent years.

\section{Several books written in the 1600 s were} donated to Texas A\&M. The volumes donated included a first folio printing in three volumes of The History of the Rebellion and Civil Wars in England, Begun in the Year 1641 by Edward Hyde, earl of Clarendon, and a first edition of The Life of the Earl of Clarendon. Hyde was an eyewitness to the events he recorded. His books are considered the "most valuable of all the contemporary accounts" of the English civil war.

\title{
FOCUS ON COLLECTIONS
}

$\mathrm{T}$ he University of Illinois at UrbanaChampaign (UIUC) Communications Library owns two advertising collections that are a rich resource of information on products advertised by numerous advertising agencies. The D'Arcy Collection is a collection of almost one million original advertisements published between 1890 and 1980. The Woodward Collection of Advertising is a collection of four million original advertisements pub-

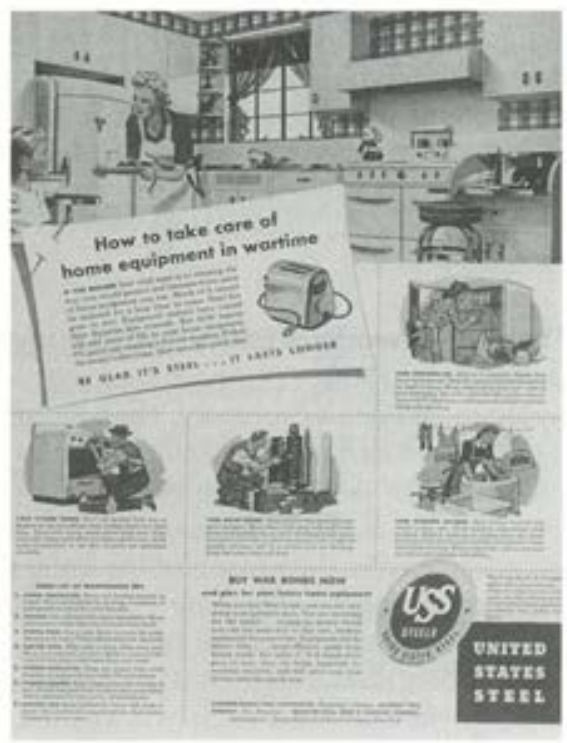

An ad from the D'Arcy Advertising Collection, a collection at the University of Illinois at Urbana-Champaign Communications Library. lished between 1880-1984. The majority of these advertisements appeared in newspapers, magazines, and trade journals.

The collections are unique in that they consist of advertisements from a variety of product and service categories including medicine, automobiles, electronics, agriculture, clothing, food and beverages, household and personal products, and technology.

The collections represent primary research materials valuable to students, researchers, and educators in advertising, history, cultural studies, women's studies, and media studies. Their value extends far beyond a record of the history of advertising. The collections are a visual archive of the progression and development of technology, and the values, lifestyles, and material culture of Americans.

Interest in the collection has originated from UIUC students and faculty, researchers from other institutions, private corporations and businesses, as well as individuals interested in the collection for personal use. Requests for information can vary from specific advertisements or brands to more general requests for items or subject material.

The Communications Library and the College of Communications Library have highlighted selected ads from these collections in an exhibit available on the Web at: http:// www.library.uiuc.edu/adexhibit. - Lisa Romero, acting communications librarian, University of Illinois at Urbana-Champaign, l-romero@uiuc.edu. 


\section{Get the Full Story Using Full Text Databases}

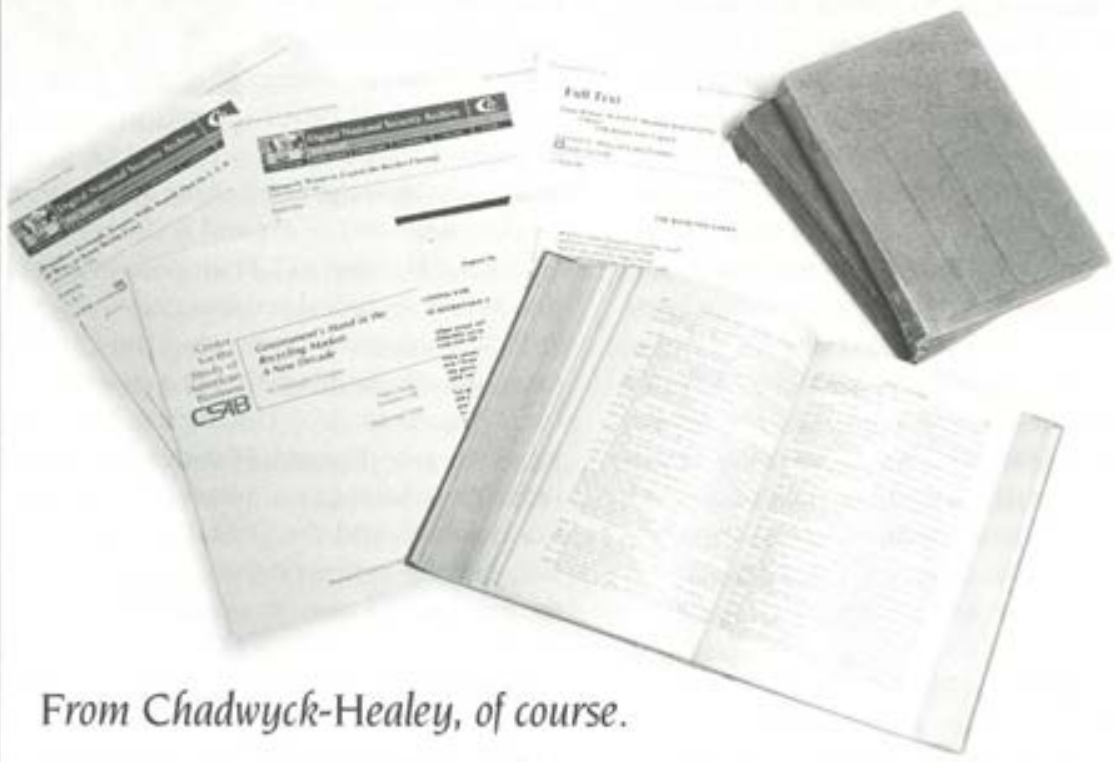

Chadwyck-Healey already provides Web access to more than 350,000 full texts of classical and contemporary literature in Literature Online. This is a constantly growing database and will grow to 10 million pages and cover more than a millennium of English-language literature.

In addition, this year we're adding 2 million pages of full-text to our music, performing arts, history, policy and reference databases. These will include current and retrospective periodical and newspaper articles, letters and memos, books and anthologies, policy reports and more.

Call today or visit our Web site for a 30-day complimentary preview of any of our new full-text databases.

www.chadwyck.com 1-800-752-0515, ext. 810

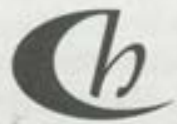

CHADWYCK-HEALEY

Home of the Humanities on the Web

1101 King Street, Suite 380, Alexandria, VA 22314-2944 